\title{
Profil persalinan pada era JKN-BPJS di RSUP Prof Dr. R. D. Kandou Manado periode 1 Januari - 30 Juni 2016
}

\author{
${ }^{1}$ Arya P. Astoguno \\ 'Joice J Kaeng \\ ${ }^{2}$ Maya Mewengkang
}

\author{
${ }^{1}$ Kandidat Skripsi Fakultas Kedokteran Universitas Sam Ratulangi Manado \\ ${ }^{2}$ Bagian Obstetri-Ginekologi Fakultas Kedokteran Universitas Sam Ratulangi Manado \\ Email: aryaba7@gmail.com
}

\begin{abstract}
JKN-BPJS stand for financing health service include childbirth is covering to examine the pregnancy, birth aid, the parturition, including family planning service post delivery and newborn service performed by health professional in health facilities. The purpose of this study was to know description of childbirth in JKN-BPJS program at Prof. Dr. R. D. Kandou. This was a retrospective descriptive study. Samples in this study were all of the mothers who used JKN-BPJS at Prof. Dr. R. D. Kandou Hospital Manado from January $1^{\text {st }}$ to June $30^{\text {th }} 2016$. The results showed that of 570 total labours, there were 422 delivery cases using JKN-BPJS program. Most mothers that used JKN-BPJS program were multigravida (58\%) at the age of 20 to 35 years $(68.25 \%)$. Most of them came directly to the hospital (44.5\%) and treated in the hospital for 4-6 days (55.7\%). Most labours handled by the JKN-BPJS program were caesarean section (50.2\%). Conclusion: Related to labours handled by the JKN-BPJS program at Prof. Dr. R. D. Kandou Hospital, most motherswere multigravida, at the age 20-35 years, came directly to the hospital, stayed in the hospital for 4-6 days, and treated with caesarean section.
\end{abstract}

Keywords: JKN-BPJS, Childbirth

\begin{abstract}
Abstrak: JKN-BPJS merupakan jaminan pembiayaan pelayanan kesehatan termasuk biaya persalinan yang meliputi pemeriksaan kehamilan, pertolongan persalinan, pelayan nifas termasuk pelayanan Keluarga Berencana (KB) paska persalinan dan pelayanan bayi baru lahir yang dilakukan oleh tenaga kesehatan di fasilitas kesehatan. Penelitian ini bertujuan untuk mengetahui profil persalinan pada era JKN-BPJS di RSUP Prof Dr. R. D. Kandou. Jenis penelitian ialah retrospektif deskriptif. Sampel penelitian yaitu semua ibu bersalin dengan program JKN-BPJS di RSUP Prof Dr. R. D. Kandou periode 1 Januari - 30 Juni 2016. Hasil penelitian menunjukkan bahwa terdapat 422 kasus persalinan menggunakan program JKN-BPJS dari total 570 persalinan. Kebanyakan persalinan dengan program JKNBPJS diikuti oleh ibu yang multigravida (58\%) dengan usia 20-35 tahun $(68,2 \%)$. Ibu yang bersalin paling banyak langsung datang sendiri ke rumah sakit $(44,5 \%)$ dan kebanyakan dirawat di rumah sakit selama 4-6 hari $(55,7 \%)$. Persalinan dengan program JKN-BPJS paling banyak ditolong dengan cara seksio sesarea $(50,2 \%)$. Simpulan: Profil Persalinan pada era JKN-BPJS di Rsup Prof Dr. R. D. Kandou kebanyakan diikuti oleh ibu multigravida, usia 20-35 tahun, langsung datang sendiri ke rumah sakit, dirawat selama 4-6 hari, dan ditolong dengan cara seksio sesarea.
\end{abstract}

Kata kunci: JKN-BPJS, persalinan.

Persentase penolong persalinan di Indonesia menurut data Riskesdas tahun
2013 yaitu dokter $(18,5 \%)$, bidan $(68,6 \%)$, perawat $(0,3 \%)$, non tenaga medis $(11,8 \%)$, 
tidak ada penolong $(0,3 \%) .{ }^{5}$ Dari data yang dipaparkan munujukkan belum tercapainya target cakupan pertolongan persalinan oleh tenaga kesehatan yang telah ditetapkan oleh pemerintah pada tahun 2014 yaitu sebesar $90 \% .^{6}$

Salah satu penyebab belum tercapainya target cakupan pertolongan persalinan tenaga kesehatan adalah masih sering terjadi kesenjangan pelayanan kesehatan di Indonesia. Saat ini masih banyak terjadi diskriminatif terhadap pasien rawat inap di rumah sakit. JKN (Jaminan Kesehatan Nasional) adalah program Pemerintah yang bertujuan memberikan kepastian jaminan kesehatan yang menyeluruh bagi seluruh rakyat Indonesia yang dilaksanakan oleh Badan Penyelenggaraan Jaminan Sosial (BPJS). Karena pelayanan kesehatan rumah sakit yang mendapatkan pasien JKN-BPJS kesehatan sudah dibayar, jadi diharapkan tidak ada perbedaan atau diskriminasi. ${ }^{8}$

Bagi perempuan yang sedang hamil program JKN-BPJS menjamin dan melindungi proses kehamilan, persalinan, pasca persalinan, penanganan perdarahan pasca keguguran dan pelayanan $\mathrm{KB}$ pasca salin serta komplikasi yang terkait dengan kehamilan, persalinan, nifas dan $\mathrm{KB}$ pasca salin. $^{9}$

RSUP Prof. Dr. R. D. Kandou Manado ialah salah satu rumah sakit rujukan di Manado yang turut memberikan JKN-BPJS kepada setiap ibu hamil yang akan bersalin hanya dengan surat rujukan, kartu BPJS, kartu keluarga, KTP, dan Buku Kesehatan Ibu dan Anak (KIA). ${ }^{1}$ Dari hasil focus group discussion (FGD) WRI di Jakarta, di mana bidan mengungkapkan bahwa jumlah pasien yang melakukan pelayanan kebidanan di poli kebidanan rumah sakit yang juga sudah menerapkan program JKN-BPJS meningkat hingga $100 \%$. Jumlah pasien sebelum adanya JKN-BPJS berkisar 40-50 per hari; sedangkan setelah JKN berkisar antara 100-130 pasien per hari. ${ }^{9}$ Berdasarkan latar belakang tersebut, penulis tertarik untuk meneliti lebih jauh mengenai Profil Persalinan pada era JKNBPJS di RSUP Prof. Dr. R. D. Kandou Manado.

\section{METODE PENELITIAN}

Jenis penelitian ini ialah deskriptif retrospektif yang bertujuan untuk melihat profil persalinan pada era JKN-BPJS di RSUP Prof. Dr. R. D Kandou Periode 1 Januari - 30 Juni 2016. Subjek penelitian ialah semua pasien dengan riwayat persalinan di Bagian Obstetri Ginekologi RSUP Prof. Dr. R. D. Kandou Manado periode 1 Januari-30 Juni 2016 dan memiliki data rekam medik lengkap di RSUP Prof. DR. R. D Kandou Manado

Variabel penelitian yang diteliti ialah persalinan dengan program JKN-BPJS berdasarkan paritas, usia ibu, cara masuk rumah sakit, jumlah hari rawat, jenis persalinan, dan luaran bayi. Data diolah dengan analisis persentase dan disajikan dalam bentuk tabel.

\section{HASIL PENELITIAN}

Persalinan dengan menggunakan program JKN-BPJS di RSU Prof Dr. R. D. Kandou Manado periode 1 Januari - 30 Juni 2016 berjumlah 422 dari total persalinan $570(74 \%)$ (Tabel 1).

Tabel 1. Insidensi persalinan dengan program JKN-BPJS

\begin{tabular}{|c|c|c|c|}
\hline \multirow[t]{2}{*}{ Tahun } & \multirow[t]{2}{*}{$\begin{array}{l}\text { Jumlah } \\
\text { Persalinan }\end{array}$} & \multicolumn{2}{|c|}{$\begin{array}{c}\text { Persalinan } \\
\text { dengan } \\
\text { program } \\
\text { JKN-BPJS }\end{array}$} \\
\hline & & $\mathbf{n}$ & $\%$ \\
\hline $\begin{array}{l}1 \text { Januari - } \\
\text { 30 Juni } 2016\end{array}$ & 570 & 422 & 74 \\
\hline
\end{tabular}

Persalinan dengan menggunakan program JKN-BPJS lebih banyak ditemukan pada multigravida, yaitu sebanyak 127 (71,3\%) (Tabel 2).

Tabel 2. Insidensi persalinan dengan program JKN-BPJS menurut paritas

\begin{tabular}{lll}
\hline Paritas & Jumlah & \% \\
\hline Primigravida & 177 & 42 \\
Multigravida & 245 & 58 \\
Total & $\mathbf{4 2 2}$ & $\mathbf{1 0 0}$ \\
\hline
\end{tabular}

Persalinan dengan menggunakan program JKN-BPJS paling banyak 
ditemukan pada ibu hamil pada kelompok usia 20-35 tahun, yaitu sebanyak 288 $(68,2 \%)$.

Tabel 3. Distribusi persalinan dengan program JKN-BPJS menurut usia ibu

\begin{tabular}{lll}
\hline Usia ibu & Jumlah & \% \\
\hline$<20$ tahun & 46 & 10,9 \\
$20-35$ tahun & 288 & 68,2 \\
$>35$ tahun & 88 & 20,9 \\
Total & $\mathbf{4 2 2}$ & $\mathbf{1 0 0}$ \\
\hline
\end{tabular}

Persalinan dengan menggunakan program JKN-BPJS paling banyak ditemukan pada ibu hamil yang masuk ke rumah sakit dengan cara datang sendiri sebanyak, $188(44,5 \%)$.

Tabel 4. Distribusi persalinan dengan program JKN-BPJS menurut cara masuk RS

\begin{tabular}{lll}
\hline Cara masuk RS & Jumlah & \% \\
\hline Rujukan dokter & 80 & 19 \\
Rujukan puskesmas & 21 & 5 \\
Rujukan RS & 133 & 31,5 \\
Datang sendiri & 188 & 44,5 \\
Total & $\mathbf{4 2 2}$ & $\mathbf{1 0 0}$ \\
\hline
\end{tabular}

Ibu hamil yang bersalin dengan menggunakan program JKN-BPJS paling banyak dirawat di RSU Prof Dr. R. D Kandou selama 4-6 hari yaitu sebanyak, $235(55,7 \%)$.

Tabel 5. Distribusi penggunaan program JKNBPJS pada persalinan berdasarkan jumlah hari rawat

\begin{tabular}{|c|c|c|}
\hline Jumlah Hari Rawat & Jumlah & $\%$ \\
\hline $1-3$ hari & 90 & 21,3 \\
\hline 4-6 hari & 235 & 55,7 \\
\hline$>6$ hari & 97 & 23 \\
\hline Total & 422 & 100 \\
\hline
\end{tabular}

Jenis pertolongan persalinan yang paling sering dilakukan dengan menggunakan program JKN-BPJS yaitu persalinan per abdominal dengan cara seksio sesarea sebanyak, $212(50,2 \%)$.

Lahiran bayi hasil dari persalinan dengan menggunakan program JKN-BPJS meninggal sebanyak 5 kasus $(1,2 \%)$ sedangkan untuk kelahiran hidup sebanyak
417 kasus $(98,8 \%)$.

Tabel 6. Distribusi persalinan dengan program JKN-BPJS menurut jenis persalinan

\begin{tabular}{lll}
\hline Jenis persalinan & Jumlah & \% \\
\hline Pervaginam: & & \\
1. Spontan & 202 & 47,9 \\
2. Ekstraksi vakum & 8 & 1,9 \\
Per abdominal: & & \\
Seksio sesarea & 212 & 50,2 \\
Total & $\mathbf{4 2 2}$ & $\mathbf{1 0 0}$ \\
\hline
\end{tabular}

Tabel 7. Distribusi lahiran bayi pada persalinan dengan program JKN-BPJS

\begin{tabular}{lll}
\hline Luaran Bayi & Jumlah & \% \\
\hline Lahiran hidup & 417 & 98,2 \\
Lahiran mati & 5 & 1,2 \\
Total & $\mathbf{4 2 2}$ & $\mathbf{1 0 0}$ \\
\hline
\end{tabular}

\section{BAHASAN}

Pada penelitian Retrospektif yang telah dilakukan di RSU Prof. Dr. R. D Kandou Manado periode 1 Januari 2016 - 30 Juni 2016 ditemukan persalinan dengan menggunakan program JKN-BPJS sebanyak 422 kasus dari 570 persalinan sehingga insidensi persalinan dengan menggunakan program JKN-BPJS sebesar $74 \%$. Hal ini menunjukkan bahwa program JKN-BPJS mulai banyak dimanfaatkan oleh masyarakat, khususnya para ibu hamil.

Pada Tabel 2, didapatkan data persalinan dengan menggunakan program JKN-BPJS periode 1 Januari - 30 Juni 2016 yaitu 177 kasus pada primigravida (42\%) dan pada multigravida lebih banyak yaitu 245 kasus (58\%). Hal ini sesuai dengan penelitian yang sebelumnya pernah dilakukan di RSUP Dr. M. Djamil Padang pada tahun 2013 lalu yang menyatakan bahwa distribusi ibu berdasarkan tingkat paritas yang paling banyak yaitu ibu dengan tingkat paritas multrigravida. ${ }^{20}$

Berdasarkan Tabel 3, data persalinan dengan menggunakan program Jampersal paling banyak ditemukan pada kelompok usia 20 - 35 tahun yaitu sebanyak 288 $(68,2 \%)$, sedangkan yang paling sedikit ditemukan pada kelompok usia $<20$ tahun yaitu sebanyak 46 kasus (10,9\%). Data ini juga sama dengan data yang ditemukan 
oleh Sunarsih dan Priska Susanaria bahwa sebagian besar ibu bersalin di RSUD Abdoel Moeloek Bandar Lampung tahun 2013 memiliki umur 20 - 35 tahun, yaitu sebesar 52,9\%. Data ini menunjukkan bahwa ibu bersalin di RSU Prof Dr. R. D Kandou telah cukup umur untuk menjalani proses persalinan. Sedangkan menurut Prawirohardjo $\mathrm{S}$ usia yang dipandang memiliki risiko saat melahirkan adalah di bawah 20 tahun dan di atas 35 tahun. Sedangkan antara 20-35 tahun dari segi usia risiko melahirkannya nol., ${ }^{3,21}$

Berdasarkan Tabel 4, terlihat distribusi persalinan dengan menggunakan program JKN-BPJS paling sedikit ditemukan pada ibu hamil yang masuk rumah sakit dengan dirujuk oleh puskesmas yaitu 21 kasus (5\%) dan terbanyak pada ibu hamil yang masuk rumah sakit dengan cara datang sendiri, yaitu 188 kasus (44,5\%). Masih banyaknya pasien dengan cara datang sendiri ke rumah sakit bisa dihubungkan dengan penelitian yang dilakukan oleh Dinas Kesehatan Provinsi DKI Jakarta bekerja sama dengan Fakultas Kedokteran Universitas Gadjah Mada (2014) menemukan adanya permintaan rujukan yang berasal dari pasien sendiri. Seringkali keluarga pasien (perempuan) peserta JKNBPJS datang ke puskesmas hanya untuk meminta surat rujukan agar bisa mengakses dan memanfaatkan pelayanan kesehatan di fasilitas kesehatan yang lebih mudah mereka akses ataau lebih dekat dari rumahnya.

Pada Tabel 5, terlihat jumlah hari rawat untuk ibu hamil yang bersalin menggunakan program JKN-BPJS selama 1-3 hari sebanyak 90 kasus (21,3\%), sedangkan paling banyak ditemukan ibu dengan jumlah hari rawat lebih 4-6 hari sebanyak 235 kasus $(55,7 \%)$ dan ibu dengan jumlah hari rawat lebih 6 hari sebayak 97 kasus (23\%).

Berdasarkan hasil survei awal berdasarkan Laporan RS dan PPK Rujukan 10 besar penyakit RI di RS/BP4/BKMM/BBKPM/BKPM/BKIM

RSI Sultan Agung Semarang tahun 2010 diketahui sebanyak $28,73 \%$ pasien memiliki masa perawatan melebihi standar INA - CBG'S, yaitu terdapat di level 1 dan 2 sebanyak 97,50\% (level LOS Jamkesmas dengan masa perawatan 5-6 hari) dan sebanyak 2,5\% level 3 (masa perawatan 7 - 8 hari, dengan tingkat komplikasi lebih banyak dan sangat berpengaruh dengan diagnosa utamanya).

Berdasarkan Tabel 6, data menunjukkan bahwa persalinan dengan menggunakan program JKN-BPJS terbanyak ditolong seksio sesarea, yaitu sebanyak 212 kasus (50,2\%). Selanjutnya pervaginam secara spontan sebanyak 202 kasus $(47,9 \%)$. Ekstraksi vakum sebanyak 8 kasus $(1,9 \%)$. Hal ini serupa dengan penelitian yang dilakukan di RSUD Tenrawaru Kabupaten Bone pada tahun menunjukkan persalinan paling banyak ditolong seksio sesarea sejumlah 393 pasien dari 660 pasien yang diteliti (60\%). WHO (World Health Organization) menganjurkan operasi sesar hanya sekitar $10-15 \%$ dari jumlah total kelahiran. Hal ini serupa dengan hasil studi di Rumah Sakit Rajawali Citra bahwa persalinan dengan seksio sesarea pada tahun 2014 meningkat dua kali lipat dibandingkan tahun 2013.

Pada Tabel 7, terlihat bahwa lahiran bayi hasil dari persalinan dengan menggunakan program JKN-BPJS ditemukan dalam keadaan lahir mati sebanyak 5 kasus $(1,2 \%)$ dari 422 total luaran bayi. Sedangkan kelahiran hidup sebanyak 417 kasus $(98,8 \%)$. Penelitian ini sesuai dengan pernyataan dr. Maxi Rondonuwu bahwa data dari dinas kesehatan provinsi Sulawesi Utara menunjukkan, sepanjang tahun 2012, Angka Kematian Bayi adalah 7 orang per seribu Kelahiran Hidup. Sementara target MDG's yang diharapkan dicapai pada 2015 , adalah sebesar 23 orang per seribu kelahiran hidup. $^{7}$

\section{SIMPULAN}

Dari hasil penelitian dan bahasan dapat disimpulkan bahwa profil persalinan pada pada era JKN-BPJS di RSU Prof. Dr. R. D Kandou umumnya diikuti oleh ibu yang multigravida, usia 20-25 tahun, langsung 
datang sendiri ke rumah sakit, dirawat selama 4-6 hari, dan ditolong dengan seksio sesarea.

\section{SARAN}

1. Mensosialisasikan pemanfaatan sistem rujukan berjenjang kepada tenaga kesehatan di FKTP dan FKTL serta kepada masyarakat peserta JKN-BPJS untuk meminimalisir kendala-kendala yang dihadapi.

2. Memperbaiki pelayanan agar rata-rata hari dimana pasien mendapatkan perawatan rawat inap di rumah sakit (aLOS) sesuai dengan standar LOS INA - CBG's.

3. Perlu diadakan penelitian lebih lanjut tentang dampak LOS pasien JKN-BPJS yang melebihi LOS INA - CBG's yang sudah di standarkan menteri kesehatan.

\section{DAFTAR PUSTAKA}

1. Mboi N. Pedoman Pelaksanaan Program Jaminan Kesehatan Nasional. Peraturan Menteri Kesehatan Republik Indonesia nomor 28/MENKES/PER/VI/2014.Jakarta:

Kementrian Kesehatan Republik Indonesia, 2014.

2. Undang-Undang Republik Indonesia Nomor 24 Tahun 2011 Tentang Badan Penyelenggara Jaminan Sosial.

3. Prawirohardjo S. Ilmu Kebidanan. Edisi 4. Jakarta: PT Bina Pustaka; 2010.

4. Moeloek NR. Rencana Strategis Kementrian Kesehatan Tahun 20152019. Keputusan Menteri Kesehatan Indonesia nomor HK.0202/MENKES/52/2015. Jakarta: Kementrian Kesehatan Republik Indonesia; 2015.

5. Riset Kesehatan Dasar 2013. Jakarta : Badan Penelitian dan Pengembangan Kesehatan Kementrian Kesehatan Republik Indonesia; 2013.

6. Profil Kesehatan Indonesia tahun 2014. Jakarta: Departemen Kesehatan Republik Indonesia; 2015.

7. Buku Saku Profil Kesehatan Sulawesi Utara tahun 2012. Manado: Dinas Kesehatan Provinsi Sulawesi Utara; 2012.

8. Azhari B. Kualitas Pelayanan Rawat Inap
Oleh Badan Penyelenggara Jaminan Sosial (BPJS) Kesehatan di Rumah Sakit Umum Pusat Haji Adam Malik Medan 2015. Medan: Universitas Sumatera Utara; 2015.

9. Pelangi B, Anindhita F, Susanti LR. Efektivitas Jaminan Kesehatan Nasional untuk Menurunkan Angka Kematian Ibu. Jakarta: Women Research Institute; 2015. p. 28.

10.Ardianty R. Analisis Implementasi Program Jamkesmas di Rumah Sakit PMI Bogor tahun 2012 [skripsi]. Jakarta: Universitas Indonesia; 2012.

11.Putra WM. Analisis Implementasi Program Jaminan Kesehatan Nasional di Rumah Sakit Umum Kota Tangerang Selatan tahun 2014 [skripsi]. Jakarta : Universitas Islami Negeri Syarif Hidayatullah; 2014.

12.Zakiah S. Faktor individual dan Faktor Struktural yang Berperan dalam Keikutsertaan Bidan Praktek Mandiri pada Program Jaminan Kesehatan Nasional di Kabupaten Tabanan [tesis]. Denpasar : Universitas Udayana; 2015.

13. Kementrian Kesehatan Republik Indonesia. Buku Pegangan Sosialisasi Jaminan Kesehatan Nasional (JKN) dalam Sitem Jaminan Sosial Nasional. Jakarta: Kementrian Kesehatan Republik Indonesia; 2014.

14.BPJS Kesehatan. Panduan Praktis Pelayanan Kebidanan dan Neonatal. Jakarta: Badan Penyelenggara Jaminan Kesehatan; 2014.

15.BPJS Kesehatan. Administrasi Klaim Fasilitas Kesehatan BPJS Kesehatan. Jakarta; Badan Penyelenggara Jaminan Kesehatan; 2014.

16.Kind $P$, William A. Health Policy. Health Policy (New York). 2004;9(March).

17.Unicef. Kesehatan Ibu \& Anak. UNICEF Indones [Internet]. 2012;(Gambar 2):1-2. Available from: http://www.unicef.org/indonesia/id/A 5_-

_B_Ringkasan_Kajian_Kesehatan_R EV.pdf

18.Kemenkes RI. Buku Pegangan Sosialisasi Jaminan Kesehatan Nasional dalam Sistem Jaminan Sosial Nasional. Dep Kesehat RI. 2013;1-75.

19.Tondolambung P. Gambaran Persalinan 
pada Program Jampersal di RSUD Prof. Dr. R. D. Kandou periode 1 April 2011 - 31 Desember 2011 [skripsi]. Manado: Universitas Samratulangi; 2011.

20.Karima NH, Machmud R, Yusrawati. Hubungan Faktor Risiko dengan Kejadian Pre-Eklampsia Berat di RSUP Dr. M. Djamil Padang [jurnal]. Padang : Universitas Andalas; 2013.

21.Sunarsih, Susanaria P. Hubungan Usia dan Paritas Ibu Hamil dengan Kejadian Pendarahan Antepartum di RSUD Abdoel Moeloek Bandar Lampung tahun 2013 [jurnal]. Bandar Lampung : Universitas Malahayati; 2015.

22.DKI Jakarta. (2014). Seminar Sistem dan Pedoman Rujukan Layanan Kesehatan Primer di Provinsi DKI Jakarta. Diakses pada 3 Januari, 2015, from http://sistem-rujukanpuskesmas-dki.net/index.php/2uncategorised/38-seminar-sistemdanpedoman-rujukan-layanankesehatan-primer-di-provinsi-dki- jakarta.

23. World Health Organization. (n.d). Referral Systems - A summary of key processes to guide health services managers. Retrieved January 4, 2014, from

www.who.int./management/referralno tes.doc

24.Bausat N. Strategi RSUD Tenriawaru Kabupaten Bone Menuju Implementasi Sistem Pembayaran Prospektif [jurnal]. Bone: RSUD Tenriawaru; 2015.

25.Apriliandini DD. Gmabaran Kemandirian Pasien dalam Tindakan Mobilisasi Dini Post Sectio Caesarea di RS Rajawali Citra Yogyakarta [skripsi]. Yogyakarta: Universitas Muhammadiya Yogyakarta; 2015.

26.Sudra, Rano Indradi. Statistik Rumah Sakit. Yogyakarta : Graha Ilmu, 2010

27.Hacker \& Moore. Fundamental of nursing; the art and science of nursing. Philadelphia: Lippincott; 2001. 